\title{
Impact of Covid-19 on the Mental Health of Indians: A Case Study
}

\author{
Saptorshi Gupta and Soham Sengupta
}

\section{ABSTRACT}

The unprecedented episode of the Covid-19 pandemic has been a massive shock to individuals all across the globe. Overwhelmed healthcare conditions, stringent lockdowns and plummeting economies have been a huge blow, especially for low- and middle-income countries. In the first phase of the pandemic, India had performed relatively better than most of the other nations in its income strata. However, the second wave of the disease had severe impacts on healthcare as well as the economy. In this light, individuals residing within the country were faced with an uphill task of evading the virus and keeping their mental health intact. This paper takes a dig into the mental health of Indian residents during the second wave of the pandemic (May 2021) through an analysis of a collected sample. The sample consisted of 400 participants $(59 \%$ males, $40.25 \%$ females; mean age $=26$ years). The DASS-21 index was used to assess the mental state of citizens amidst an ongoing nationwide lockdown. A significant association was obtained between Covid-19, depression and overall DASS index. Thus, the importance of addressing mental health issues during a prevailing pandemic has been identified, and subsequent policy recommendations have been prescribed.

Keywords: Covid-19, depression anxiety stress index, lockdown, mental health, pandemic.

\section{INTRODUCTION}

The Covid-19 pandemic has been an absolute carnage for India and its citizens. The sudden surge of Covid-19 cases in India leading to an exponential rise in people affected lead to more than 4,00,000 daily new cases as of May 1, 2021 [1]. Poor access to testing, backlogs in test results and refraining from getting tested due to fear and stigma led to the underrepresentation of an already concerning number of cases [2], [3]. Ranging from stringent lockdowns, food shortages, a massive rise in unemployment to an even deadlier second wave, overwhelmed medical facilities, oxygen shortages and huge incidence of deaths, the country has borne it all in the last couple of years. As fate would have it, the situation has been exacerbated through plummeting conditions of the economy [4]. While dealing with such unprecedented public health emergencies, public fear and depression due to uncertainty, spine-chilling visuals of fatality and lack of public health preparedness has risen by leaps and bounds.

It is of no surprise that any large-scale disaster is bound to have significant harmful impacts on the mental health of individuals. Instances of distress, anxiety, insomnia and other psychological problems have been widely reported across several nations [5]. Few past studies [6] on the bearings of quarantine on patients' mental health have consistently reported adverse psychological effects in the form of posttraumatic stress symptoms, misperception, and antagonism. The Covid-19 pandemic and its tackling methodologies in rigorous lockdowns have led to the rise in depression, loneliness and domestic abuse_[6].

Psychological distress is indicative of emotional suffering primarily resulting in symptoms of depression and anxiety [7]. Unprecedented occurrences like lockdown, home confinement, lack of mobility, staying away from family in some cases, fear of contraction of the virus, loss of employment, unreliable sources of income and witnessing deaths of friends or family members had affected the overall wellbeing of individuals [8]. Although the rise in Covid-19 cases and its associated effects on mental health were apparent, the issue had not received sufficient attention [9]. In these lines, somewhat generalized conceptual studies have been published from India. However, there has been a lack of empirical evidence on the mental health issues cropping up from Covid-19.

\section{Situation OF COVID-19}

\section{A. Covid-19 around the Globe}

The Covid-19 pandemic is believed to have a significantly harmful effect on public mental health, leading to 
psychological crises [10]. Studies conducted to examine psychological disorders during the pandemic have unanimously identified depression, trauma, mood swings, irritability, post-traumatic stress and anger as the significant symptoms [11]-[13]. Moreover, research has also associated agony due to frequent exposure to media [14]. Studies conducted in China show that fear associated with the unknown nature of the virus can lead to mental disorders [15]. Among older adults, as has been found in a study in the Netherlands, personal losses, fret relating to the pandemic and a reduction in trust in government are associated with increased problems on mental health [16].

Psychiatrist Marcella Rietschel from the Central Institute for Mental Health, Germany, states that anguish during pandemic crops up mainly due to limited social interactions, tensions among families in lockdown, and fear of illness. The Office for National Statistics data states that about one in every five adults in the United Kingdom were suffering from depression in June 2020. This sudden surge in 9 percentage points of the depression index directly impacted the Covid19 pandemic (Fig. 1). Mental health conditions in the United States of America were even calamitous. As per data collected by the Centre for Disease Control and Prevention in December 2020, over 4 in 10 [17] individuals had symptoms of anxiety or depression, marking a surge of 11 per cent [17] compared to the previous year. America was under a heavy burden of diseases during this time as about 2 lakh cases were reported daily. The incidence of the Covid-19 and impending danger of life was profoundly responsible for individuals' aggravating mental health conditions.
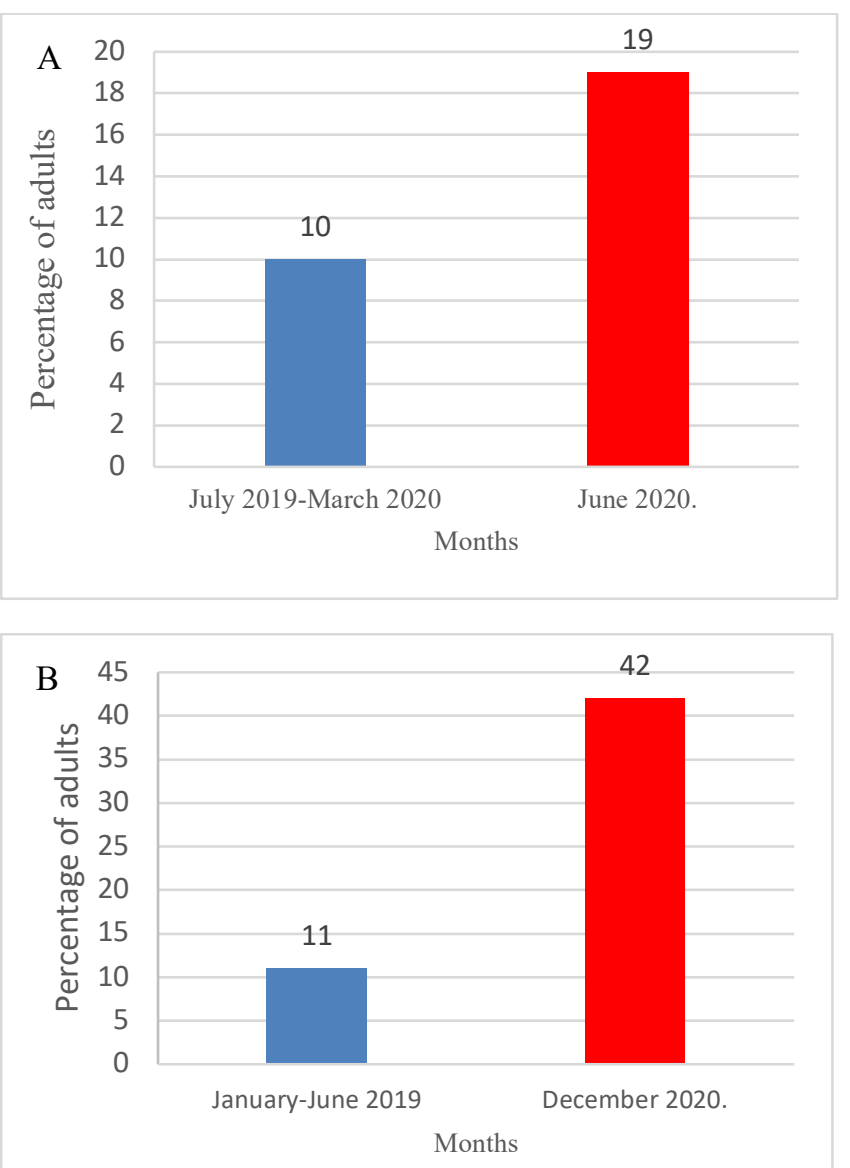

Fig. 1. A. Percentage of adults reporting depression (United Kingdom); B. Percentage of adults reporting anxiety or depression (USA).

\section{B. Covid-19 in India}

Recurrent extensions in lockdown and intimidating social media news on Covid-19 in India have resulted in lengthier periods of curbed movements and prolonged self-isolation measures. Some studies [18] have pointed towards worsening mental health conditions due to protracted epochs of isolation and restricted mobility. Although aggravating mental health circumstances are visible among Indian adults, the impact of extended lockdown is likely to differ across vulnerable groups [19]. To make matters worse, the patriarchal societal setup of India paves the way to increased risk of domestic abuse [20], resulting in prolonged exposure to the threat of domestic violence. Worsening the mental health of women is inevitable in such settings. The conceptual framework below explains the various routes to poor mental health and its repercussions during the Covid-19 pandemic situation in India.

\section{CAse Study}

\section{A. Study Design}

We included 400 participants in this study to assess the mental health conditions of Indian citizens during the second wave of the Covid-19 crisis in May 2021. At that point in time, the country witnessed about 4 lakh daily cases, thousands of deaths, and crumbling medical health infrastructure. Risk of life, loss of employment, worrying financial conditions and stringent lockdowns had severe effects on the mental health conditions of Indian residents. This study is a snapshot of poor mental health conditions experienced by Indians during the second wave of Covid-19.

\section{B. Participants}

Individuals residing in India during the Covid crisis in May 2021 were eligible for the study. It is noteworthy to mention that the country had seen about 4 lakh daily cases, thousands of deaths, and crumbling medical health infrastructure by this time. A total of 400 participants voluntarily agreed to take part in the study.

\section{Data Collection}

A self-administered questionnaire was used for obtaining the Depression-Anxiety-Stress Scale (DASS) index of the participants as of May 2021. Written informed consent was obtained from the study subjects. Answers from each respondent were digitally saved and analyzed subsequently. Interviews were carried out using Google forms. Participants in this study had the choice of scoring each of the 21 questions [21] on a scale of 0 (did not apply to me at all) to 3 (applied to me very much). These 21 questions were segregated into three subgroups of seven questions for depression, anxiety and stress scale. Finally, scores were summed up to obtain the DASS-21 index summary. Cutoff scores [21] were obtained from the severity ratings suggested by Lovibond and Lovibond. Cutoff scores of 13, 9 and 16 were taken as cutoff points for extremely severe depression, anxiety and stress subscale. 


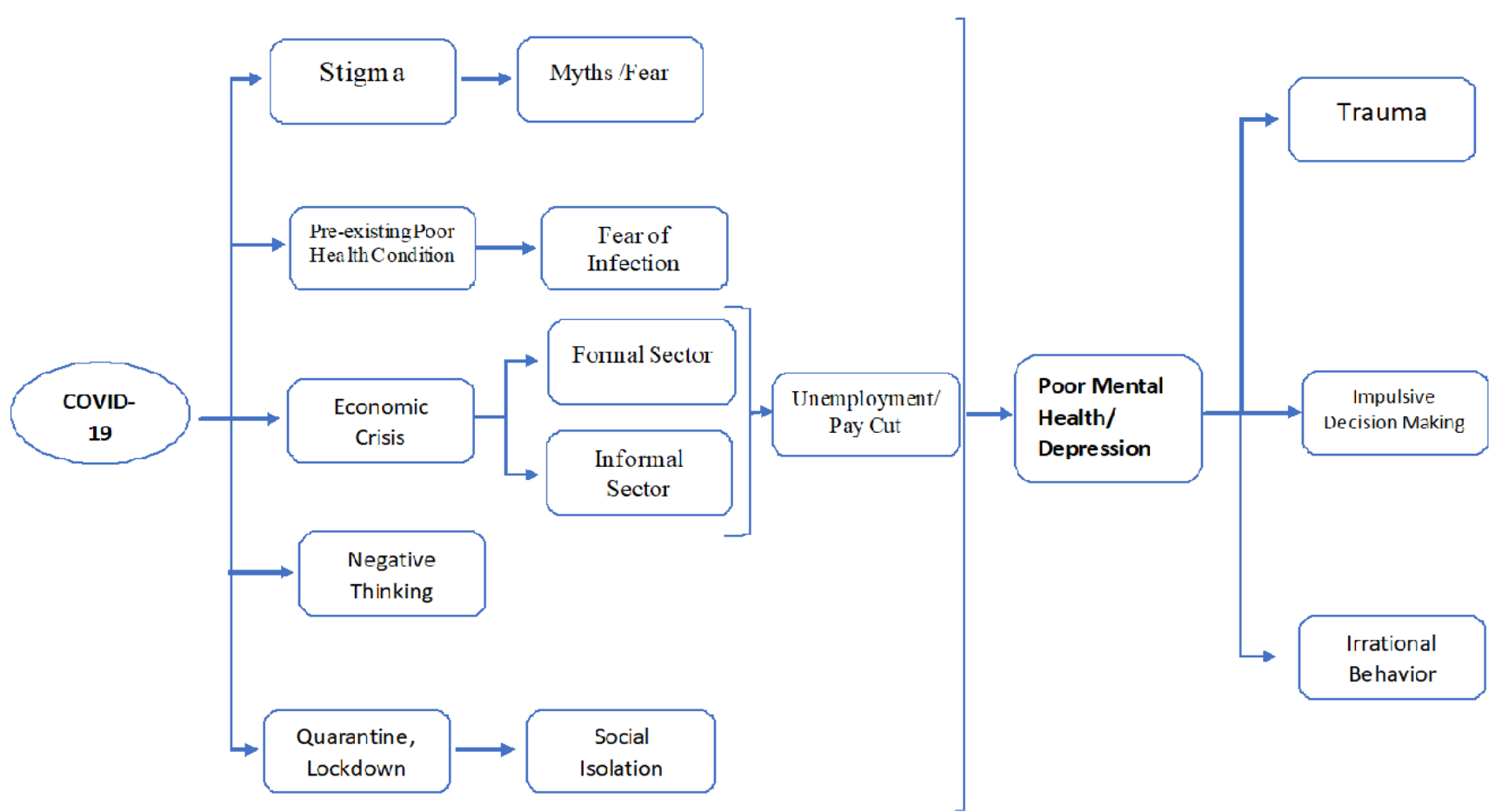

Fig. 2. Conceptual Framework of Covid-19 leading to poor mental health.

\section{Statistical Analysis}

Data analysis in this study was conducted with the help of MINITAB-17, SPSS-26 and MS-Excel software. Missing values were non-existent in the dataset since all questions in the questionnaire were compulsory. The DASS-21 index for each participant was obtained through the summation of scores of all three subgroups. A chi-square test was performed to assess the association between the incidence of Covid-19 in the last 14 days and mental health. After that, the test was repeated on the total DASS score and contracting the disease. The test was carried out at a 5\% significance level.

\section{RESUlts}

\section{A. Summary Statistics}

The study involved 236 males (59\%) and 161 females $(40.25 \%)$. Because the rampage of Covid-19 had dissipated across the entire population demography, individuals from younger ages were also interviewed in this study. The mean age of participants in the study was about 25 years. Our sample had a case-positivity rate of 8.5 per cent (Table I).

\begin{tabular}{cc} 
TABLE I: SUMMARY STATISTICS OF THE PARTICIPANTS \\
\hline \hline Gender (\%) & 59 \\
Male & 40.25 \\
Female & 0.75 \\
Non-Binary & \\
Age & 24.788 \\
Mean & 10.28 \\
SD & 41.47 \\
Coeff. Variation & 65 \\
Range & 2.69 \\
Skewness & 7.1 \\
Kurtosis & \\
Covid Status (\%) & 8.5 \\
Infected & 91.5 \\
Not Infected & \\
\hline \hline
\end{tabular}

Source: Data collected and analyzed by the authors.

\section{B. Categorical Analysis}

A categorical analysis of the effect of Covid-19 on DASS Indices revealed a strong association of Covid-19 and incidence of depression (Pearson Chi-Square=15.088, PValue $=0.005)$. However, it is surprising to find that levels of anxiety (P-value=0.399) and stress (0.109) had no association with the prevailing situation of Covid-19 (Table II).

TABLE II: CATEGORICAL ANALYSIS OF THE EFFECT OF COVID ON DASS INDICES

\begin{tabular}{|c|c|c|c|c|c|c|}
\hline \multicolumn{7}{|c|}{ DEPRESSION LEVEL } \\
\hline & Mild & Moderate & Normal & Severe & $\begin{array}{l}\text { Extremely } \\
\text { Severe }\end{array}$ & All \\
\hline No & 40 & 77 & 124 & 44 & 81 & 366 \\
\hline Yes & 4 & 4 & 7 & 12 & 7 & 34 \\
\hline All & 44 & 81 & 131 & 56 & 88 & 400 \\
\hline \multicolumn{7}{|c|}{ Pearson Chi-Square $=15.088, \mathrm{DF}=4, \mathrm{P}-$ Value $=0.005$} \\
\hline \multicolumn{7}{|c|}{ ANXIETY LEVEL } \\
\hline & Mild & Moderate & Normal & Severe & $\begin{array}{l}\text { Extremely } \\
\text { Severe }\end{array}$ & All \\
\hline No & 25 & 77 & 154 & 36 & 74 & 366 \\
\hline Yes & 4 & 9 & 9 & 5 & 7 & 34 \\
\hline All & 29 & 86 & 163 & 41 & 81 & 400 \\
\hline \multicolumn{7}{|c|}{ Pearson Chi-Square $=4.053, \mathrm{DF}=4, \mathrm{P}-$ Value $=0.399$} \\
\hline \multicolumn{7}{|c|}{$\begin{array}{l}\text { STRESS LEVEL } \\
\end{array}$} \\
\hline & Mild & Moderate & Normal & Severe & $\begin{array}{l}\text { Extremely } \\
\text { Severe }\end{array}$ & All \\
\hline No & 43 & 68 & 166 & 61 & 28 & 366 \\
\hline Yes & 5 & 9 & 9 & 10 & 1 & 34 \\
\hline All & 48 & 77 & 175 & 71 & 29 & 400 \\
\hline
\end{tabular}

Here, it is essential to note that the association is established concerning a meagre sample size of just 400 individuals. A study with a bigger sample size may produce even significant and more robust associations. However, without any doubt, it is safe to state from the results that mental state did exacerbate significantly due to the pandemic and its repercussions. The contingency table shows that 
$16.5 \%(n=66)$ of the respondents had a significant DASS level, out of which Covid infected $53.03 \%(n=35)$ in the last 14 days. 3 of the 34 non-infected individuals infected by Covid in the previous fortnight had non-significant levels of DASS index. Results from table 3 indicate that the incidence of Covid-19 exacerbates mental health conditions (pvalue $=0.000$ ).

TABLE III: EFFECT OF COVID-19 ON TOTAL DASS SCORE (OVERALL

\begin{tabular}{cccc}
\multicolumn{4}{c}{ MENTAL HEALTH) } \\
\hline \hline & $\begin{array}{c}\text { Significant } \\
\text { DASS level }\end{array}$ & $\begin{array}{c}\text { Non-Significant } \\
\text { DASS Levels }\end{array}$ & All \\
\hline $\begin{array}{c}\text { Not infected by Covid } \\
\text { Infected by Covid in } \\
\text { the last 14 days }\end{array}$ & 35 & 331 & 366 \\
All & 31 & 3 & 34 \\
\hline \hline
\end{tabular}

Pearson Chi-Square $=150.402, \mathrm{DF}=1, \mathrm{P}-$ Value $=0.000$

Source: Data collected and analyzed by the authors

\section{RECOMMENDATIONS}

In light of the current distress and turmoil, it is essential to keep the right frame of mind and hang on till this situation subsides. Tackling mental health crises in the form of prevention and diagnosis is of paramount importance. The World Health Organization (WHO) has recommended few strategies to maintain good mental health during this pandemic. Engagement in routine activities, indulging in pastimes, developing newer interests, staying connected to friends and family through social media, staying calm, working out and abstaining from alcohol or drug use are some pointers to deal with emotional complications. In short, four primary deterrent approaches are required for maintaining healthier mental wellbeing among a population:

- planning for loneliness;

- developing surveillance mechanism;

- reporting and intervention_for individuals at risk or abuse;

- reinforcing mental health system to prepare for challenges posed by Covid-19.

Government intervention is of utmost importance as a steadfast arrangement of psychological and mental health helplines for resolving mental health issues at the personal and community level during lockdown can turn out to be tremendously beneficial.

\section{CONCLUSION}

The Covid-19 pandemic coupled with confinement and lack of mobility has been detrimental to the mental health condition of individuals. As significant evidence has been found between the associations of incidence of Covid-19 and crumbling mental health conditions, it is essential to clinically diagnose patients who have contracted the disease and ensure a good state of mind for them. Vulnerable sections of the population like children and older adults need more attention in these trying times. In addition, marginalized sections of the society and vulnerable people like women (especially in male-dominated societies) deserve prompt attention. Overall, a multidimensional health care model involving the physiological, psychological, and social health of patients and communities is the need of the hour. Public policy programmes intended to cater to the needs of the citizens through the provision of critical services can help ease out the situation.

\section{Data AVAilability}

Kindly note that primary data is used by the authors collected during the second wave of the Covid-19 pandemic in India. Raw data can be accessed at: https://datadryad.org/stash/share/dataset/doi:10.5061/dryad. h70rxwdjv.

\section{ETHICAL CONSIDERATIONS}

This was an online survey, and hence the participation in the survey was on an entirely voluntary basis. Further, no sensitive information was collected as a part of this study, and the participants' identity was utterly anonymous. Informed consent and complete anonymity were maintained to respect the confidentiality of the participants. Therefore, the authors consider that ethical clearance is not required for such studies.

\section{ACKNOWLEDGMENT}

The project was completed with the help and support of a lot of people and we would like to acknowledge their contributions heartily. S.S. would like to convey special thanks to Ankita Ghosh for her timely recommendations. S.S. and S.G. is immensely grateful towards Shuvarghya Ghosh for providing valuable insights regarding methodologies of research. We are also grateful towards Sherry Mangla for proofreading our work.

\section{REFERENCES}

[1] H. Ritchie, E. Ortiz-Ospina, D. Beltekian, E. Mathieu, J. Hasell, and B. Macdonald, "India: Coronavirus pandemic country profile", 2021.

[2] S. Jamkhandikar and D. Ghoshal, "Many Indians struggle to get coronavirus tests as cases rocket." Reuters, Retrieved from: https:/www.reuters.com/world/india/many-indians-struggle-getcoronavirus-tests-cases-rocket-2021-04-20/, (2021)

[3] "The New India Express. Fear, stigma, laxity contribute to rising Covid-19 cases." Retrieved https:/www.newindianexpress.com/states/odisha/2021/may/11/fearstigma-laxity-contribute-to-rising-covid-19-cases-2301129.html, 2021

[4] M. Chaudhary, P. R. Sodani and S. Das S. "Effect of COVID-19 on Economy in India: Some Reflections for Policy and Programme." Journal of Health Management. 22(2):169-180, 2020.

[5] R. Rossi, V. Socci, D. Talevi, S. Mensi, C. Niolu, F. Pacitti and G. Di Lorenzo, "COVID-19 pandemic and lockdown measures impact on mental health among the general population in Italy." Frontiers In Psychiatry 11, 790, 2020.

[6] S. Das "Mental Health and Psychosocial Aspects of COVID-19 in India: The Challenges and Responses." Journal of Health Management 22(2):197-205, 2020.

[7] B. Dohrenwend and B. Dohrenwend "Perspectives on the past and future of psychiatric epidemiology. The 1981 Rema Lapouse Lecture.” American Journal Of Public Health 72, 1271-1279, 1982.

[8] S. Grover, S. Sahoo, A. Mehra, A. Avasthi, A. Tripathi, A. Subramanyan and Y. J. Reddy "Psychological impact of COVID-19 lockdown: An online survey from India." Indian Journal Of Psychiatry 62, 3542020.

[9] C. Wang, R. Pan, X. Wan, Y. Tan, L. Xu, C. S. Ho and R. C. Ho, "Immediate psychological responses and associated factors during the initial stage of the 2019 coronavirus disease (COVID-19) epidemic 
among the general population in China." International Journal of Environmental Research And Public Health 17, 1729, 2020.

[10] Y. T. Xiang, Y. Yang, W. Li, L. Zhang, Q. Zhang, T. Cheung and C. H. Ng, "Timely mental health care for the 2019 novel coronavirus outbreak is urgently needed." Lancet Psychiatry 7(3):228-9, 2020.

[11] S. K. Brooks, R. K. Webster, L. E. Smith, L. Woodland, S. Wessely, N. Greenberg and G. J. Rubin, "The psychological impact of quarantine and how to reduce it: rapid review of the evidence." Lancet 14;395(10227):912-20, 2020.

[12] Y. Wang, B. Xu, G. Zhao, R. Cao, X. He and S. Fu "Is quarantine related to immediate negative psychological consequences during the 2009 H1N1 epidemic?” Gen Hosp Psychiatry 33(1):75-7, 2011.

[13] G. J. Rubin and S. Wessely "The psychological effects of quarantining a city." BMJ 368:m313, 2020.

[14] Y. Neria and G. M. Sullivan, "Understanding the mental health effects of indirect exposure to mass trauma through the media." JAMA 306(12):1374-5, 2011.

[15] J. Shigemura, R. J. Ursano, J. C. Morganstein, M. Kurosawa and D. M. Benedek, "Public responses to the novel 2019 coronavirus (2019$\mathrm{nCoV}$ ) in Japan: mental health consequences and target populations." Psychiatry Clin Neurosci 74(4):281, 2020.

[16] T. G van Tilburg, S. Steinmetz, E. Stolte, H. van der Roest and D. H. de Vries, "Loneliness and Mental Health During the COVID-19 Pandemic: A Study Among Dutch Older Adults", The Journals of Gerontology: Series B 76(7), e249-e255, 2021.

[17] A. Abbott. "COVID's mental-health toll: how scientists are tracking a surge in depression." Nature 590, 194-195. 2021.

[18] A. Shankar, A. McMunn, J. Banks and A. Steptoe, "Loneliness, social isolation, and behavioral and biological health indicators in older adults." Health Psychology 30(4), 377-385. 2011.

[19] A. Gopal, A. J. Sharma and M. A. Subramanyam, "Dynamics of psychological responses to COVID-19 in India: A longitudinal study." PLoS ONE 15(10): e0240650. 2020.

[20] S. Nigam, "COVID-19: India's Response to Domestic Violence Needs Rethinking.” South Asia Journal 2020.

[21] S. H. Lovibond and P. F. Lovibond, "Manual for the Depression Anxiety Stress Scales." Sydney Psychology Foundation Australia 1996. 